\title{
BMJ Open Four sexually transmitted infections (STIs) in Belgian general practice: first results (2013-2014) of a nationwide continuing surveillance study
}

\author{
N Boffin, ${ }^{1}$ S Moreels, ${ }^{1} \mathrm{~J}$ Deblonde, ${ }^{2}$ V Van Casteren ${ }^{1}$
}

To cite: Boffin N, Moreels S, Deblonde J, et al. Four sexually transmitted infections (STIS) in Belgian general practice: first results (2013-2014) of a nationwide continuing surveillance study. BMJ Open 2017;7:e012118. doi:10.1136/bmjopen-2016012118

- Prepublication history for this paper is available online. To view these files please visit the journal online (http://dx.doi.org/10.1136/ bmjopen-2016-012118).

Received 31 March 2016 Revised 26 October 2016 Accepted 8 November 2016

CrossMark

\begin{abstract}
${ }^{1}$ Department of Health Services Research, Scientific Institute of Public Health, Brussels, Belgium

${ }^{2}$ Department of Epidemiology of Infectious Diseases, Scientific Institute of Public Health, Brussels, Belgium
\end{abstract}

Correspondence to Dr N Boffin; nicole.boffin@wiv-isp.be

\section{ABSTRACT}

Objectives: To describe and explore data from the surveillance of chlamydia, syphilis, gonorrhoea and genital warts by the Belgian Network of Sentinel General Practices (SGP) over the first 2 years (2013 and 2014) and to estimate the incidence of these 4 sexually transmitted infections (STIs). A special focus is put on data quality.

Design: Retrospective observational study.

Setting: General practices from the nationwide representative SGP network.

Outcome measures: Agreement between data distributions by year, agreement between SGP-based incidence and incidence based on mandatory notification, missingness of patient age or gender and incompleteness of sexual risk history of patients.

Results: 306 new STI episodes were reported from 298 patients, corresponding with an episode-based incidence of $91.9 / 100000$ (95\% Cl 81.9 to 102.8) general practice patients, with almost half of it due to chlamydia. The incidence of chlamydia in men was significantly higher in 2014 than in 2013. Population characteristics were similarly distributed in 2013 and 2014. The SGP-based incidence of gonorrhoea and syphilis in Flanders were in agreement with the incidence based on mandatory notification of cases. Patient age or gender was missing from 35 episodes $(11.4 \%)$. Independent determinants of missingness of patient age or gender were the Flemish region (OR 3.46 ; $95 \% \mathrm{Cl} 1.02$ to 11.73$)$ and genital warts infection (OR 2.23; 95\% Cl 1.07 to 4.63). An incomplete sexual risk history was reported for $54.6 \%$ STI episodes. The odds for an incomplete sexual history were higher for older patients (OR 1.72; 95\% Cl 1.06 to 2.76) and for patients infected with syphilis, gonorrhoea or co-infection(s) (OR 1.71; 95\% Cl 1.03 to 2.83 ).

Conclusions: Incompleteness of reports about patients with STI sexual risk histories is important from the perspective of quality of data and of quality of care. Together with the low rates of both HIV testing and discussion of partner notification, this suggests that a general practice guideline is needed.

\section{Strengths and limitations of this study}

- The first nationwide general practice-based study on patients with sexually transmitted infection in Belgium.

- Relatively small study population, many missing values, some concepts on the reporting form were not defined.

- The Belgian Network of Sentinel General Practices (SGP)-based incidence for gonorrhoea and syphilis in Flanders were in agreement with mandatory notification data.

- High incompleteness of sexual risk histories, findings about HIV testing and partner notification suggest that a general practice guideline is needed.

\section{INTRODUCTION}

For two decades the incidence of sexually transmitted infections (STIs) in Europe has been increasing. The most frequently reported STIs in Europe remain Chlamydia trachomatis, followed by gonorrhoea and syphilis, with an overall rate in 2013 of, respectively, 181.7 (chlamydia), 16.9 (gonorrhoea) and 5.4 (syphilis) per 100000 persons. ${ }^{1}$

Like in other countries, the surveillance of STIs in Belgium is ensured by multiple systems with mandatory STI case reporting by clinicians at its core. ${ }^{2}$ Within the Belgian Scientific Institute of Public Health (IPH), the surveillance of STIs has been carried out by the Belgian Network of Sentinel Laboratories for Microbiology since 1983 and by the Network of Sentinel STI Clinics/ Clinicians since 2000. Participants in the latter network include caregivers at all levels of care, that is, general practitioners (GPs), specialised medical doctors (gynaecology, dermatology, internal medicine and urology), centres for sexual health and family 
planning, STI clinics and student medical services. The low number of GPs participating in the Network of Sentinel STI Clinics/Clinicians raised concerns about the coverage of the general practice population. Therefore, it was decided to also include the surveillance of four STIs in the IPH-based programme of the wellestablished Belgian Network of Sentinel General Practices (SGP) from 2013 onwards. Following the model of the surveillance by the Network of Sentinel STI Clinics/Clinicians, the SGP surveillance study of STIs aims to monitor both the epidemiology and characteristics of patients and GP care.

GPs play a key role in Belgian healthcare, even though patients are basically free to consult any care provider. Overall, $95 \%$ of the general population in Belgium has a regular GP and around half of all general practice patients have a 'general health record', that is, a GP-held record of all their medical information including reports from other care providers. ${ }^{3}{ }^{4}$ In contrast to the Netherlands, no general practice guideline for STI care is available in Belgium. However, a general practice guideline 'early detection of chlamydia trachomatis' was disseminated in the northern part of Belgium (Flanders) and early detection of STIs was part of a guideline 'prenatal care' that was disseminated on the national level. ${ }^{56}$

In this paper we describe and explore data from the STI surveillance by the SGP over the first 2 years and we estimate the corresponding incidence. This exploration should help to understand the results and to optimise the continuing surveillance study. Relying on a review of methods and dimensions of data quality assessment, we focus on the quality of the reported data. ${ }^{7}$ In terms of this framework, we consider the dimensions concordance and plausibility of data by examining the agreement between the study data by year and between the study data and data from another source. For the latter examination, we compare the incidence estimates derived from the SGP surveillance with the incidence rates based on the available mandatory notification data. The dimension's completeness was highlighted by examining missing data. Item data may not be reported by the sentinel GPs because they were skipped or overlooked. This is most probably the reason why patients' age or gender is not always reported. As a result, incidence rates by gender cannot be estimated unless data imputation is used. Reports of patients' sexual risk history may be incomplete because sentinel GPs are not aware of these details. Belgian GPs were found to be reluctant to openly discuss sexual issues with patients. ${ }^{8-10}$ The prime concern of data missingness is whether the available data would be biased, or, oppositely, whether they are missing at random. ${ }^{11}$ An incomplete sexual risk history may also be seen as a negative quality indicator since sexual history taking is an essential part of STI care. Therefore, we explored the characteristics of patients and GP care that are associated with missingness of age or gender and an incomplete sexual risk history.
METHODS

\section{Data source}

The Belgian network of SGP was developed in 1979 by the Belgian IPH drawing on international experiences of sentinel surveillance. ${ }^{12}$ The SGP network comprises $\sim 150$ general practices with one or more sentinel GPs who purposively record routine clinical care data for the surveillance of specific health problems or care delivery. One advantage of this type of sentinel surveillance is that it allows to collect contextual information from patients and the care they receive that is not available in their electronic health record (EHR). The gender-age distributions of sentinel and non-sentinel GPs by region are comparable and the network covers between $1.4 \%$ and $1.8 \%$ of the Belgian population throughout all regions. The territorial distribution of the SGP network over Belgium by population density is also fairly representative. ${ }^{13}$ As Belgian GPs do not serve a defined practice population, the size of the SGP patient population is estimated by applying the ratio of patient contacts in the entire Belgian population to the sum of weekly patient contacts in the network.

\section{Data collection}

The design and conceptualisation of this study was guided by the surveillance study by the Network of Sentinel STI Clinics/Clinicians. The data were reported by the SGP on weekly paper forms. SGPs were instructed to include all patients with a new episode of laboratoryconfirmed chlamydia, gonorrhoea or syphilis. No laboratory confirmation was needed to include patients with genital warts. A 1 month follow-up form was sent out to report HIV test results that were unknown when the patient was reported.

\section{Variables and measures}

Generic variables were patients' gender, age, educational level and country of birth, and the Belgian region of the SGP. The measure 'patient age or gender missing' was given a value of 1 if the SGP failed to report one or both patient characteristics.

STI-specific study variables were diagnosis, reason for encounter (RFE), sexual risk history, HIV serological status and discussion of partner notification.

For all four possible diagnosis, sentinel GPs were asked to report whether this was the first infection or a reinfection. Reinfection was not defined. We regrouped STI diagnoses into four categories of monoinfections and a fifth category of 'co-infection' if more than one of four STI diagnoses was made.

The RFE is the main reason for which the patient with STI visited the GP. Two types of the patients' RFE were displayed on the registration form. Precoded options for non-symptom-based RFE were screening, prenatal STI test and a partner with STI. Precoded options for symptom-based RFE were urethritis/epididymitis, proctitis, cervicitis/vaginitis and genital ulcer. In addition to precoded RFE, options were available to report 'other' 
non-symptom-based and 'other' STI-related symptombased RFE. No free-text space was foreseen to describe these 'other' RFE. Aspects of sexual risk history on the form included place of infection acquisition (Belgium or abroad); sexual orientation (homosexual, heterosexual, bisexual); number of sexual partners in the past 6 months (zero, one, two to four, five or more); use of condom in general (yes, no); steady relation (yes, no); sex worker (SW; yes, no); sexual contact(s) with SW (yes, no); sexual contact(s) with drug injecting person (s) (yes, no); drug injecting (yes, no). In this study, having contact(s) with SW and performing as SW were considered together as one characteristic given the small number of cases 13 and 4, respectively. The same applies to having contacts with drug injecting person(s) and injecting drugs oneself, given the small number of cases 4 and 1, respectively. An option 'unknown' was displayed for all aspects of sexual risk history, except for place of infection acquisition. Since there was no statistically significant association between unreported sexual behaviour and reported 'unknown' sexual behaviour (data not shown), both values were considered together. A sexual risk score was computed by summing the scores $(0$ is no risk and 1 means risk is present) on the individual items and dichotomising this sum into a dummy variable based on the median value of the population. Patients with a sexual risk score of 1 are thus at higher risk than those with a score of 0 . We used a similar approach for the measure 'incompleteness of sexual risk history', that is, by summing the missing values on the individual items ( 0 is valid value and 1 means value is missing) and dichotomising this sum into a dummy variable based on the median value of the population. Patients with a value of 1 thus have a more incomplete sexual risk history than those with a score of 0 .

On the form, three issues were displayed under the heading 'HIV serological status': time of the HIV test, test result and, if applicable, the reason why no HIV test was taken. In this paper we describe HIV serological status as never having had a test, recently having had a test without results yet, HIV negative and positive. Possible reasons for not having had a HIV test were patient refusal, no proposal by the GP and having a test planned. Discussion of patient notification was worded on the form as 'discussion of informing and treatment of sexual partner'.

\section{Analysis}

Multiple logistic regression was used to identify factors related to unreported (vs unknown) sexual risk history, and to four patient (care) characteristics, respectively, STI reinfection, a high sexual risk score, never being tested for HIV and not having discussed partner notification. In the model exploring determinants of never being tested for HIV, persons without a (planned) test were compared with patients who were HIV negative. Multiple logistic regression was also used to identify factors related to the missingness of patient age or gender and incompleteness of sexual risk history. Variables in all $(\mathrm{n}=7)$ full models included the variables which were (borderline) significantly $\left(\chi^{2}\right.$ test $\left.p<0.10\right)$ associated with that measure or a dependent variable. Interaction effects between independent variables were tested in all models. A generalised estimating equation approach was used to account for the clustering of data within SGPs. ${ }^{14}$ We used Poisson CIs to compare the distribution of the population characteristics by year. The incidence was estimated by dividing the number of STI episodes by the sum of the person years covered by the SGP in the concerned period. CIs for incidence rates were calculated using a Poisson distribution. To estimate the incidence rates by gender, missing values for gender were replaced by the expected gender using the available data from that person. In all cases, imputation was based on the STI diagnosis, for example, $87.1 \%$ of all syphilis diagnosis occurred in men. All incidence rates were compared by year. The SGP-based incidence estimates were compared with available mandatory notification data of gonorrhoea and syphilis in the same period. At the time of analysis (December 2015), these data were only available for Flanders, the largest region of Belgium. Data were analysed using Stata V.13.

\section{RESULTS}

Over a 2-year period, 306 new STI episodes were reported by 83 of 140 SGPs $(59.3 \%)$ and no STIs were reported by 57 SGPs $(40.7 \%)$. Most SGPs $(n=132)$ had participated both years. The 306 reported STI episodes concerned 298 patients. More than one STI episode was reported from seven persons, that is, one person with three episodes and six with two episodes.

\section{Population characteristics}

Among the monoinfection episodes, chlamydia (43.1\%) was the most common (table 1). Nine of 17 co-infections involved both chlamydia and gonorrhoea. Eight of 47 reinfections $(17.0 \%)$ were reported as a second or third STI episode in the study period. As a result, 39 of 47 $(83.0 \%)$ reinfections concerned persons that had been infected with the same STI before 2013. Independent determinants of reinfections were involvement in homosexual or bisexual behaviour (OR 2.74; 95\% CI 1.11 to $6.76)$ and engagement in SW (OR 4.91; $95 \%$ CI 1.47 to 16.36). Most STI (65\%) were diagnosed following an encounter that was symptom-based, with urethritis/ epididymitis as the most common symptom (29.7\%). Non-symptom-based RFE were reported for $43.7 \%$ of all episodes, with screening as the most important $(20.0 \%$; table 1). Taken together, in 81 of 306 (26.5\%) episodes another, non-specified RFE was reported, symptombased or not.

The most common sexual risk was not using a condom (81.2\%). The only independent determinant of a higher sexual risk score than the population median was being a man (OR 2.37; 95\% CI 1.16 to 4.83 ). 
Table 1 Characteristics of new episodes of patients with STI reported by the SGP in 2013-2014 (N=306)

\begin{tabular}{|c|c|c|c|}
\hline & \multicolumn{2}{|l|}{ Row \% (95\% Cl) } & \multirow{2}{*}{$\begin{array}{l}\text { Total } \\
\mathbf{n}(\%)\end{array}$} \\
\hline & 2013 & 2014 & \\
\hline \multicolumn{4}{|l|}{ Gender (valid $n=279$ ) } \\
\hline Men & 56.1 (43.6 to 71.0$)$ & $58.3(47.0$ to 71.6$)$ & $160(57.3)$ \\
\hline Women & 43.9 (33.0 to 57.3 ) & 41.7 (32.2 to 53.1$)$ & $119(42.7)$ \\
\hline Missing values & & & $27(8.8)$ \\
\hline \multicolumn{4}{|l|}{ Age in years (valid $n=295$ ) } \\
\hline$<25$ & $38.5(28.8$ to 50.5$)$ & 37.5 (28.6 to 48.3$)$ & $112(38.0)$ \\
\hline $25-44$ & $48.1(37.2$ to 61.4$)$ & 49.4 (39.1 to 61.5$)$ & $144(48.8)$ \\
\hline$\geq 45$ & 13.3 (7.9 to 21.1$)$ & 13.1 (8.1 to 20.1$)$ & 39 (13.2) \\
\hline Missing values & & & $11(3.6)$ \\
\hline \multicolumn{4}{|l|}{ Educational level (valid $n=210$ ) } \\
\hline Primary or lower & 6.9 (2.8 to 14.3$)$ & $1.8(0.2$ to 6.6$)$ & $9(4.3)$ \\
\hline Secondary & 47.5 (35.0 to 63.0$)$ & 56.9 (43.6 to 72.9$)$ & $110(52.4)$ \\
\hline Tertiary or higher & 45.5 (33.3 to 60.8$)$ & 41.3 (30.1 to 55.2$)$ & $91(43.3)$ \\
\hline Missing values & & & 96 (31.4) \\
\hline \multicolumn{4}{|l|}{ Country of birth (valid $n=295$ ) } \\
\hline Belgium & $85.2(70.3$ to 1.00$)$ & 80.6 (67.3 to 95.8$)$ & $244(82.7)$ \\
\hline Other country & 14.8 (9.0 to 22.9$)$ & $19.4(13.2$ to 27.5$)$ & $51(17.3)$ \\
\hline Missing values & & & $11(3.6)$ \\
\hline \multicolumn{4}{|l|}{ STI diagnoses (valid $n=306$ ) } \\
\hline Chlamydia & 36.7 (27.3 to 48.2$)$ & 48.5 (38.5 to 60.3$)$ & $132(43.1)$ \\
\hline Gonorrhoea & 20.1 (13.4 to 29.1$)$ & $14.4(9.2$ to 21.4$)$ & $52(17.0)$ \\
\hline Syphilis & $12.2(7.1$ to 19.6$)$ & $8.4(4.6$ to 14.1$)$ & $31(10.1)$ \\
\hline Genital warts & 28.1 (20.0 to 38.4$)$ & $21.0(14.6$ to 29.1$)$ & 74 (24.2) \\
\hline Co-infection & $2.9(0.8$ to 7.4$)$ & $7.8(4.1$ to 13.3$)$ & $17(5.6)$ \\
\hline Missing values & & & $0(0.0)$ \\
\hline Reinfection (valid n=306) & 12.9 (7.7 to 20.5$)$ & 17.4 (11.6 to 24.9$)$ & $47(15.4)$ \\
\hline Missing values & & & $0(0.0)$ \\
\hline \multicolumn{4}{|l|}{ RFE or STI-related symptoms (valid $n=300$ ) } \\
\hline Screening (patient-initiated) & 16.9 (10.7 to 25.4$)$ & 22.6 (15.9 to 31.1$)$ & $60(20.0)$ \\
\hline Prenatal STI test & $2.9(0.8$ to 7.5$)$ & $1.2(0.0$ to 4.4$)$ & $6(2.0)$ \\
\hline Partner with STI & 12.5 (7.3 to 20.0$)$ & 15.9 (10.4 to 23.2$)$ & $43(14.3)$ \\
\hline Other RFE (non-symptom-based) & $9.6(5.1$ to 16.3$)$ & $6.1(2.9$ to 11.2$)$ & $23(7.7)$ \\
\hline Any of 4 non-symptom-based RFE & 41.2 (31.1 to 53.5$)$ & 45.7 (36.0 to 57.3$)$ & $131(43.7)$ \\
\hline Urethritis/epididymitis & 29.4 (21.0 to 40.0$)$ & 29.9 (22.1 to 39.5$)$ & $89(29.7)$ \\
\hline Proctitis & $0.3(0.0$ to 7.5$)$ & $0.6(0.0$ to 3.4$)$ & $5(1.7)$ \\
\hline Cervicitis/vaginitis & 12.5 (7.3 to 20.0$)$ & 10.4 (6.0 to 16.6$)$ & $34(11.3)$ \\
\hline Genital ulcer & $8.1(4.0$ to 14.5$)$ & $5.5(2.5$ to 10.4$)$ & $20(6.7)$ \\
\hline Other symptoms & $19.1(12.5$ to 28.0$)$ & $22.0(15.4$ to 30.4$)$ & $62(20.7)$ \\
\hline Any of 5 symptom-based RFE & 67.6 (54.5 to 83.0$)$ & 62.8 (51.3 to 76.2$)$ & $195(65.0)$ \\
\hline Missing values & & & $6(2.0)$ \\
\hline \multicolumn{4}{|l|}{ Sexual risk history } \\
\hline Infection acquired abroad (valid $n=293$ ) & $6.1(2.6$ to 12.0$)$ & $8.0(4.3$ to 13.7$)$ & $21(7.2)$ \\
\hline Missing values & & & $13(4.3)$ \\
\hline Homosexual or bisexual contacts (valid $n=278$ ) & 20.5 (13.4 to 30.0$)$ & $12.6(7.6$ to 19.6$)$ & 45 (16.2) \\
\hline Missing values & & & $28(9.2)$ \\
\hline$\geq 2$ sex partners in last 6 months (valid $n=191$ ) & $36.0(24.6$ to 50.8$)$ & $40.2(28.8$ to 54.5$)$ & $73(38.2)$ \\
\hline Missing values & & & $115(37.6)$ \\
\hline No condom use (valid $n=229$ ) & 80.6 (64.2 to 99.9$)$ & $81.7(66.7$ to 99.1$)$ & $186(81.2)$ \\
\hline Missing values & & & 77 (25.2) \\
\hline No steady relation (valid $n=257$ ) & 40.7 (30.0 to 53.9$)$ & 46.8 (36.1 to 59.6$)$ & $113(44.0)$ \\
\hline Missing values & & & $49(16.0)$ \\
\hline (Contact with) SW (valid n=240) & $6.3(2.5$ to 13.0$)$ & 7.0 (3.2 to 13.2$)$ & $16(6.7)$ \\
\hline Missing values & & & $66(21.6)$ \\
\hline (Contact with) drug injecting person (valid $n=259$ ) & $0.0(-3.1)^{\star}$ & $3.6(1.2$ to 8.3$)$ & $5(1.9)$ \\
\hline Missing values & & & $47(15.4)$ \\
\hline \multicolumn{4}{|l|}{ Sexual risk score $(0-7)$ (valid $n=139)$} \\
\hline$\geq$ Median & 52.5 (35.9 to 74.1$)$ & $51.3(36.6$ to 69.8$)$ & $72(51.8)$ \\
\hline
\end{tabular}




\begin{tabular}{|c|c|c|c|}
\hline & \multicolumn{2}{|l|}{ Row \% (95\% Cl) } & \multirow{2}{*}{$\begin{array}{l}\text { Total } \\
\text { n (\%) }\end{array}$} \\
\hline & 2013 & 2014 & \\
\hline \multicolumn{4}{|l|}{ HIV serologic status (valid $n=287$ ) } \\
\hline Never tested & 30.3 (21.6 to 41.3$)$ & 35.5 (26.7 to 46.2$)$ & $95(33.1)$ \\
\hline No results yet & 3.8 (1.2 to 8.8$)$ & 5.8 (2.7 to 11.0$)$ & $14(4.9)$ \\
\hline HIV positive & $4.5(1.7$ to 9.9$)$ & $6.5(0.0$ to 3.6$)$ & $7(2.4)$ \\
\hline Missing values & & & $19(6.2)$ \\
\hline \multicolumn{4}{|l|}{ Reason absence HIV test (valid $n=65$ ) } \\
\hline Refusal & $4.3(0.0$ to 24.2$)$ & 9.5 (2.6 to 24.4$)$ & $5(7.7)$ \\
\hline Not proposed by GP & $34.8(15.0$ to 68.5$)$ & 57.1 (36.6 to 85.0$)$ & $32(49.2)$ \\
\hline Test is planned & 60.9 (33.3 to 100$)$ & 33.3 (18.2 to 56.0$)$ & $28(43.1)$ \\
\hline Flanders (vs Wallonia/Brussels) & 77.0 (63.1 to 93.0$)$ & 75.4 (62.9 to 89.8$)$ & $233(76.1)$ \\
\hline Missing values & & & $0(0.0)$ \\
\hline
\end{tabular}

One in three patients $(33.1 \%)$ had never been tested for HIV seropositivity. Excluding those episodes $(n=28)$ for which a HIV test was planned, 67 of 287 (23.3\%) never had a test (planned). Compared with patients who were HIV negative, persons without a (planned) test were more likely to have visited their GP because of a partner with STI (OR 2.92; 95\% CI 1.05 to 8.13) and to have a lower risk by their sexual behaviour (OR 2.52; $95 \%$ CI 1.02 to 6.20 ).

GPs did not discuss partner notification in $8.7 \%$ of all episodes. Patient involvement in SW was the only independent determinant of not discussing partner notification (OR 6.21; 95\% CI 1.72 to 22.43 ).

\section{Incidence of four STls}

In the Belgian general practice population of 2013-2014, the episode-based incidence of four STIs was estimated at 91.9/100 000 patients (table 2). Chlamydia had the highest incidence among both women and men. The incidence of gonorrhoea and syphilis was significantly higher among men than among women. Incidence rates by year were similar except for chlamydia. The overall incidence of chlamydia was significantly higher in 2014 compared with 2013 (56.8/100 000; 95\% CI 45.9 to 69.6 vs $31.9 / 100000 ; 95 \%$ CI 23.9 to 41.6$)$. This increase was observed among men (52.3/100 000; 95\% CI 37.7 to 70.7 vs $22.8 / 100000 ; 95 \%$ CI 13.8 to 35.7$)$ but not among women $(61.2 / 100000 ; 95 \%$ CI 45.6 to 80.5 vs $40.6 / 100000 ; 95 \%$ CI 28.2 to 56.4$)$.

\section{Quality of data}

As measured by CI, there were no statistically significant differences between the distributions of the population characteristics by year (table 1 ).
There was agreement between the incidence rates based on the SGP surveillance and the incidence rates based on the mandatory notification of gonorrhoea and syphilis in Flanders in 2013-2014 (table 3).

Gender or age was missing from 35 of 306 episodes (11.4\%; table 1). Independent determinants of missingness of patient age or gender were the Flemish (vs the Walloon and Brussels) region (OR 3.46; 95\% CI 1.02 to 11.73) and genital warts infection (OR 2.23; $95 \%$ CI 1.07 to 4.63$)$.

The highest proportion of missing values in the sexual risk history was found for the number of sex partners in the past 6 months $(37.6 \%)$ and condom use $(25.2 \%$; table 1). In 167 of 306 episodes $(54.6 \%)$ one or more aspects of sexual risk history were missing. Being above median age (OR 1.72; 95\% CI 1.06 to 2.76) and being infected with syphilis, gonorrhoea or being co-infected (OR 1.71; 95\% CI 1.03 to 2.83) were independent determinants of an incomplete sexual risk history.

\section{DISCUSSION}

In the Belgian general practice population of 20132014, the episode-based incidence of four STIs was estimated at 91.9/100 000 patients and almost half of the incidence was due to chlamydia. The incidence of chlamydia in men was significantly higher in 2014 than in 2013. The population characteristics in 2013 and 2014 were similarly distributed. The SGP-based incidence estimates of gonorrhoea and syphilis in Flanders were in agreement with the estimates based on the mandatory notification data in the same period. Values for age or gender and sexual risk history were not missing at random. Relatively more SGPs in Flanders did not 
Table 2 Episode-based incidence of four STIs per 100000 patients in the Belgian general practice population by (imputed) gender in 2013-2014

\begin{tabular}{llcr}
\hline & All & Women & Men \\
\hline Chlamydia & $44.1(37.3-51.9)$ & $50.7(40.6-62.6)$ & $37.3(28.5-47.9)$ \\
Genital warts & $24.0(19.0-29.9)$ & $28.1(20.6-37.5)$ & $20.0(13.9-28.0)$ \\
Gonorrhoea & $18.9(14.5-24.2)$ & $\mathbf{7 . 1 ( 3 . 7 - 1 2 . 4 )}$ & $\mathbf{2 1 . 2 ( 2 3 . 2 - 4 1 . 0 )}$ \\
Syphilis & $9.9(6.8-13.9)$ & $78.4(1-6.9)$ & $\mathbf{1 7 . 1}(11.4-24.7)$ \\
Any of four STIS & $91.9(81.9-102.8)$ & $77.8(65.1-92.3)$ & $105.8(90.6-122.8)$ \\
Person-based STI incidence & $89.5(79.6-100.2)$ & $101.5(86.7-118.2)$ \\
\hline
\end{tabular}

STI, sexually transmitted infection.

Non-overlapping confidence intervals are in bold.

report patient age or gender (11.4\% overall). More importantly, for $54.6 \%$ of all STI episodes an incomplete sexual risk history was reported. The odds for an incomplete sexual history were higher for older patients and for patients infected with syphilis, gonorrhoea or co-infected patients. We found that persons without a (planned) HIV test $(23.3 \%$ of all episodes) were more likely to have visited their GP because of an infected partner and to be at lower STI risk by their sexual behaviour. Not discussing partner notification (8.7\% of all episodes) was only associated with patient engagement in SW.

\section{Strengths and limitations of the study}

This is the first nationwide general practice-based study on the epidemiology of four STIs and GP care for patients with STI in Belgium. It is based on usual care data reported by a network of GPs that is representative of the national workforce. Therefore, our findings can be generalised to the general practice population. It remains to be determined whether they can be generalised to the general population, although there is agreement between the SGP-based incidence estimates for gonorrhoea and syphilis and those based on mandatory notification in the general population. Possibly less patients with STI have a regular GP compared with the general population, and oppositely, GPs may see relatively more STI-infected persons that are not regular patients. The latter may explain the high number of missing values in this study.

This study has several weaknesses. The conceptual framework we used does not provide unambiguous criteria to label the dimensions (correctness, completeness, concordance, plausibility and currency) that are covered by data quality studies. ${ }^{7}$ The agreement between the SGP data distributions by year and between the
SGP-based incidence estimates and the incidence estimates based on mandatory notification data may be seen as reflecting the dimensions concordance as well as plausibility. The framework was set up for EHR data assessment and therefore the methods and dimensions are not completely transferable to other routinely collected health data. ${ }^{15}$

The number of STI episodes was relatively small and high proportions of item data were not reported. As a result, we were unable to estimate STI incidence rates by age groups and by regions. In this study only missingness of age or gender and sexual risk history were explored. Yet, the number of missing values was equally high for the educational level of patients $(31.4 \%)$ and the reason why no HIV test was performed (31.6\%). The completeness of item data is now monitored continuously and requests for missing values are sent out to the SGPs. The considerable proportions of unspecified 'other' RFE show that the precoded RFE options were insufficient to capture the patients' motivation for seeking care. Free-text fields were added on the study forms to describe 'other' RFE. Some concepts on the registration form were not defined, for example, 'reinfection' and 'episode'. A consensus about these definitions is being developed together with the Network of Sentinel STI Clinics/Clinicians and will be implemented in the surveillance by both networks. Several of these weaknesses are typical for studies that are based on usual care data, such as the surveillance by the Network of Sentinel STI Clinics/Clinicians which was used as a model to set up this SGP surveillance study. Yet, provider-reported data are commonly used in epidemiological research on STIs since they offer quantitative and contextual information on hidden and socially stigmatised populations and can be done on rather low budgets. ${ }^{2}$

Table 3 Episode-based incidence of gonorrhoea and syphilis per 100000 general practice patients in Flanders (SGP data) compared with the incidence per 100000 inhabitants in Flanders based on mandatory notification data in 2013-2014

\begin{tabular}{|c|c|c|c|c|}
\hline & \multicolumn{2}{|c|}{ Gonorrhoea } & \multicolumn{2}{|c|}{ Syphilis } \\
\hline & SGP & Mandatory notification & SGP & Mandatory notification \\
\hline Women & $8.1(3.7-15.5)$ & $8.3(7.6-9.0)$ & $3.6(1.0-9.3)$ & $2.1(1.8-2.5)$ \\
\hline Men & $36.2(25.7-49.4)$ & $31.1(29.7-32.5)$ & $18.5(11.3-28.6)$ & $13.1(12.2-14.0)$ \\
\hline
\end{tabular}


Comparison with existing literature

The SGP-based incidence rates are highly comparable with the overall and sex-specific incidence rates for chlamydia (reported by countries with low rates) and gonorrhoea and syphilis (reported by countries with high rates) in regularly reporting European Union countries in 2013. ${ }^{1}$ A longitudinal STI surveillance study in England during 2000-2011 showed comparable chlamydia incidence rates for women in general practice in $2011(43.8 / 100000,95 \%$ CI 43.1 to 44.7$)$, the overall and male rates of chlamydia were also lower but differed significantly (overall $29.3 / 100000,95 \%$ CI 28.8 to 29.7 ; in men $14.3 / 100000,95 \%$ CI 13.8 to 14.7 ) with our findings. ${ }^{16}$ General practice incidence rates from 2010 in the Netherlands were much higher for chlamydia $(176.2 / 100000)$ and genital warts $(134.1 / 100000)$ but similar for gonorrhoea $(21.9 / 100000) .{ }^{17}$ Sex-specific incidence rates of patients with STI consulting Dutch GPs in 2006 were comparable for gonorrhoea and syphilis. ${ }^{18}$ The SGP incidence estimates of genital warts were far below the median incidence values (overall 194.5/ 100000 ; for women 120.5/100 000; for men 137/ $100000)$ described in a recent review. ${ }^{19}$

\section{Implications for future research and clinical practice}

In the near future, the profile of patients with STI in general practice according to the SGP will be compared with the profile of patients with STI receiving care in specialised care settings according to the Network of Sentinel STI Clinics. Differences between the profile of patients with STI in general practice and those treated in specialised STI centres were found in the Netherlands. ${ }^{18} 20$

Negligence of the sentinel GPs is undoubtedly insufficient to explain the very incomplete sexual risk history of patients. As described before, the reluctance of Belgian GPs to openly discuss sexual issues with patients was evidenced. ${ }^{6} 810$ Our study suggests that this is more difficult when patients are older or (co-)infected with syphilis or gonorrhoea, maybe even more marked by shame and stigma than other STIs. Recently, a practical tool was developed in Flanders to support GPs in disclosing (deviant) sexual practices of their patients with STI. ${ }^{21}$ Our findings suggest that time has come for a general practice guideline on STI management, including recommendations on HIV testing and discussing of partner notification.

\section{CONCLUSIONS}

Incidence rates for four STIs were estimated for the first time in the Belgian general practice population. The data of this surveillance study form the baseline to keep on monitoring the epidemiology of four STIs and STI care by GPs. One finding is that the sentinel GPs did report highly incomplete sexual risk histories of their patients with STI. This is important from the perspective of data quality and also from a quality of care perspective as it suggests that GPs are largely unaware of the sexual risk history of STI-infected patients.

Acknowledgements All GPs from the Belgian Network of Sentinel General Practices are gratefully acknowledged.

Contributors NB, SM and VVC were involved in the study conception, study design, data collection, interpretation of results and finalisation of the manuscript. JD was involved in the critical revision of the manuscript. NB and SM were also involved in the data analyses and writing the manuscript.

Funding The study was funded by the Flemish Agency for Care and Health and the French Federation of Brussels and the Walloon region.

Competing interests None declared.

Ethics approval Ethical Committees of the Scientific Society of Flemish GPs and the Catholic University of Louvain (UCL).

Provenance and peer review Not commissioned; externally peer reviewed.

Data sharing statement No additional data are available.

Open Access This is an Open Access article distributed in accordance with the Creative Commons Attribution Non Commercial (CC BY-NC 4.0) license, which permits others to distribute, remix, adapt, build upon this work noncommercially, and license their derivative works on different terms, provided the original work is properly cited and the use is non-commercial. See: http:// creativecommons.org/licenses/by-nc/4.0/

\section{REFERENCES}

1. European Centre for Disease Prevention and Control. Sexually transmitted infections in Europe 2013. Stockholm: ECDC, 2015.

2. Lowndes CM, Fenton KA. Surveillance systems for STIs in the European Union: facing a changing epidemiology. Sex Transm Infect 2004;80:264-71.

3. Belgian Health Interview Survey-interactive analysis HISIA. Brussels: Scientific Institute of Public Health. https://hisia.wiv-isp.be/ SitePages/Home.aspx (accessed 17 Feb 2016).

4. Meeus P. Performantie van de huisartsgeneeskunde. Een check-up [General practice performance. A check up]. Brussel: RIZIV, 2012.

5. Seuntjens L, Neirinckx J, Van Mackelenbergh A, et al. Richtlijn Zwangerschapsbegeleiding [Guideline prenatal care]. Huisarts $\mathrm{Nu}$ 2006;35:261-98.

6. Verhoeven V, Avonts D, Peremans L, et al. Richtlijn Actieve opsporing van chlamydia trachomatis in de huisartsenpraktijk. [Guideline active detection of chlamydia trachomatis in general practice]. Huisarts Nu 2004;33:182-99.

7. Weiskopf NG, Weng C. Methods and dimensions of electronic health record data quality assessment: enabling reuse for clinical research. J Am Med Inform Assoc 2013;20:144-51.

8. Coenen S, Vermeire K, Bovijn K, et al. A lot of barriers for STDregistration in primary care. Int J Infect Dis 2004;8(Suppl I):S65-6.

9. Verhoeven V, Colliers A, Verster A, et al. Collecting data for sexually transmitted infections (STI) surveillance: what do patients prefer in Flanders? BMC Health Serv Res 2007;7:149.

10. Vos J, Pype P, Deblonde J, et al. Collecting and registering sexual health information in the context of HIV risk in the electronic medical record of general practitioners: a qualitative exploration of the preference of general practitioners in urban communities in Flanders (Belgium). Prim Health Care Res Dev 2016;17:333-50.

11. Altman DG, Bland JM. Missing data. BMJ 2007;334:424.

12. Van Casteren V. Thirty years Registration Network of Sentine General Practitioners. Arch Public Health 2009;67(Suppl 2):3-15.

13. Boffin N, Moreels S, Van Casteren V. The Belgian network of Sentinel General Practices between 2007 and 2012: a short report. Brussels: Scientific Institute of Public Health, OD Public Health and Surveillance, Health Services Research, 2013.

14. Zeger SL, Liang KY, Albert PS. Models for longitudinal data: a generalized estimating equation approach. Biometrics 1988;44:1049-60.

15. Benchimol El, Smeeth L, Guttmann A, et al. The REporting of studies Conducted using Observational Routinely-collected health Data (RECORD) statement. PLoS Med 2015;12:e1001885.

16. Wetten $\mathrm{S}$, Mohammed $\mathrm{H}$, Yung $\mathrm{M}$, et al. Diagnosis and treatment of chlamydia and gonorrhoea in general practice in England 20002011: a population-based study using data from the UK Clinical Practice Research Datalink. BMJ Open 2015;5:e007776. 
17. van Bergen JE, Dekker J, Boeke JKJ, et al. NHG-Standaard Het SOA consult (eerste herziening). [NHG-Standard the STI consult (first revision)]. Huisarts Wetenschap 2013;56:450-63.

18. van den Broek IV, Verheij RA, van Dijk CE, et al. Trends in sexually transmitted infections in the Netherlands, combining surveillance data from general practices and sexually transmitted infection centers. BMC Fam Pract 2010;11:39.

19. Patel $\mathrm{H}$, Wagner $M$, Singhal $\mathrm{P}$, et al. Systematic review of the incidence and prevalence of genital warts. BMC Infect Dis 2013;13:39.
20. Trienekens SC, van den Broek IV, Donker GA, et al. Consultations for sexually transmitted infections in the general practice in the Netherlands: an opportunity to improve STI/HIV testing. BMJ Open 2013;3:e003687.

21. Anonymous. Seksueel overdraagbare infecties [Sexually transmitted infections]. Antwerpen: Domus Medica, 2015. http://www. domusmedica.be/vorming/vorming-voor-lok-s/736-diensten handleidingen-voor-lok-s-new/doe-het-zelf-lok-paketten/ 6190-seksueel-overdraagbare-infecties.html (accessed 19 Feb 2016). 